\title{
PROTOTYPE BAHAN AJAR BAHASA INDONESIA BERORIENTASI DUNIA KERJA KEPARIWISATAAN UNTUK SISWA KELAS X SMK
}

\author{
I Gede Nurjaya ${ }^{1}$, , \\ 1 Universitas Pendidikan Ganesha
}

\begin{abstract}
Abstrak
This research and development was done with the aim of developing tourism sector oriented instructional material for the tenth grade students at SMK Program Keahlian UPW in Denpasar City. To achieve the aim, a study was done to identify the tourism instructional material and Indonesian material that is relevant to the development of Indonesian instructional material for the tenth grade students at SMK Program Keahlian Usaya Pelayanan Wisata in Denpasar City. In the second year, using document analysis method and panel group discussion, Indonesian instructional material for the tenth grade students at SMK Program Keahlian Usaya Pelayanan Wisata in Denpasar City had been developed The basic framework of the material is as follows: (1) the use of thematic approach to cover the theme of tourism in the Indonesian textbook, (2) the use of text based Indonesian instructional material development, (3) the use of scientific approach in implementing text based instructional material. The prototype designed has good validity when it was judged by relevant judges. With the findings, it is suggested that in developing instructional material with other orientations the instructional material development has to be adapted to the design of the prototype found in this study.
\end{abstract}

\author{
Keywords: \\ prototype, instructional \\ material, job sector, \\ tourism
}

\section{PENDAHULUAN}

Konsep pembelajaran bahasa sudah berkembang sampai kepada pembelajaran bahasa untuk tujuan-tujuan khusus. Hal ini dapat dilihat pada model pembelajaran bahasa Inggris untuk tujuan khusus (ESP). Pembelajaran bahasa Indonesia semestinya juga mengarah kepada model pembelajaran ini. Hal ini sesuai dengan amanat kurikulum pada jenjang SMK yang mengarahkan peserta didiknya untuk siap terjun di dunia kerja. Kesiapan terjun di dunia kerja tentu harus ditopang oleh pemberian bekal yang didapatkan dari mata pelajaran yang dipelajari sewaktu peserta didik mengikuti persekolahan, khususnya di SMK. Oleh karena itulah, mata pelajaran apapun yang diberikan pada satuan pendidikan ini seharusnya mengarah kepada kesiapan peserta didik untuk terjun di dunia kerja yang ditargetkan. Pelajaran bahasa Indonesia yang merupakan salah satu mata pelajaran pokok nonkejuruan semestinya menunjang juga kesiapan peserta didik untuk tujuan tersebut. Kurikulum untuk mata pelajaran bahasa Indonesia pada satuan pendidikan SMK dengan jelas menekankan arah pengajaran seperti di atas. Hal ini, misalnya, dapat dicermati dari Standar Kompetensi Lulusan (SKL) mata pelaharan Bahasa Indonesia tingkat SMK, yang selalu diembeli dengan pernyataan "yang berkaitan dengan pekerjaan".

SKL di atas memberikan petunjuk bahwa pembelajaran bahasa Indonesia pada semua jenis keterampilan berbahasa diarahkan kepada kemampuan berkomunikasi dalam dunia kerja. Model pembelajaran bahasa seperti ini sudah begitu intens diterapkan pada pembelajaran bahasa Inggris untuk tujuan khusus (ESP). Kenyataan yang ada sekarang, model pembelajaran dan juga segenap perangkat pembelajaran bahasa Indonesia di SMK ternyata sama saja dengan model pembelajaran dan perangkat pembelajaran pada sekolah umum (SMA). Pelajaran bahasa Indonesia kurang terlibat dalam menunjang keahlian yang dibutuhkan oleh siswa setelah mereka memasuki dunia kerja. Ada kesan, pelajaran bahasa 
Indonesia sepertinya hanya merupakan mata pelajaran wajib yang ikut di UN-kan. Kesan ini tentu sangat negatif karena akan menimbulkan kekurangseriusan siswa maupun guru untuk mempelajari maupun mengajarkan bahasa Indonesia. Bahasa adalah alat komunikasi. Oleh karena itu, belajar bahasa haruslah belajar berkomunikasi. Komunikasi yang perlu lebih intens dipelajari tentu saja komunikasi yang berkaitan dengan dunia kerja seseorang. Komunikasi umum biasanya sudah bukan halangan untuk siswa setingkat SMK.

Untuk dapat membawa pelajaran bahasa Indonesia ikut menunjang skill yang dibutuhkan lulusan SMK untuk terjun di dunia kerja, maka pelajaran bahasa Indonesia haruslah dikemas menjadi mata pelajaran yang aplikatif untuk bidang pekerjaan siswa nantinya. Pengemasan pelajaran itu membutuhkan segenap perangkat pembelajaran yang memiliki fokus yang sama yaitu meningkatkan keterampilan siswa untuk di dunia kerja. Salah satu perangkat pembelajaran yang penting adalah buku ajar. Untuk menghasilkan bahan ajar yang diharapkan, penelitian ini telah dilakukan sebanyak dua tahap. Tahap I tahun 2014, telah berhasil mengidentifikasi bahan ajar bahasa Indonesia dan kepariwisataan serta menemukan tingkat relevansinya. Pada tahun ke 2 ini, penelitian diarahkan kepada pengembangan prototype dan uji validitas dari prototype yang dikembangkan. Untuk keperluan tersebut, teori yang melandasi adalah teori tentang bahan ajar seperti diuraikan di bawah ini.

\section{METODE PENELITIAN}

Penelitian ini menggunakan Rancangan Penelitian Pengembangan dengan Model 4-D (Define, Design, Develop, and Desseminate) oleh Thiagarajan, etal (1974). Pada tahun ke II dari penelitian ini, telah sampai ke tahap design yaitu berupa pengembangan prototype bahan ajar bahasa Indonesia berorientasi dunia kerja kepariwisataan untuk siswa kelas X SMK Program Keahlian UPW di Kota Denpasar. Kegiatannya berupa (1) Perancangan prototype bahan ajar bahasa Indonesia yang berorientasi dunia kerja kepariwisataan untuk siswa SMK jurusan Kepariwisataan di Bali, (2) Analisis kesesuaian (Validasi Ahli), (3) Memperbaiki draf prototipe bahan ajar bahasa Indonesia berdasarkan masukan ahli. Untuk uji ahli terhadap prototype dilakukan oleh (1) praktisi pembelajaran bahasa Indonesia, (2) praktisi pembelajaran kepariwisataan, (3) pakar pendidikan bahasa Indonesia.

\section{ANALISIS DAN PEMBAHASAN}

\section{Pengembangan Prototype Buku Ajar Bahasa Indonesia Berorientasi Dunia Kerja Kepariwisataan untuk Siswa SMK Kepariwisataan}

Dalam pengembangan prototype buku ajar ada beberapa langkah yang ditempuh. Langkah pertama adalah analisis terhadap Silabus, Rencana Pelaksanaan Pembelajaran, dan pendekatan pembelajaran sesuai amanat Kurikulum 2013. Hal ini dilakukan untuk mengetahui model tataan materi pembelajaran dalam perencanaan pembelajaran (silabus dan RPP) serta kesesuaiannya dengan langkah pendekatan saintifik. Dari analisis terhadap dokumen di atas maka didapatkan hasil sebagai berikut. (1) Tataan materi pembelajaran bahasa Indonesia dalam RPP belum memenuhi persyaratan yang diharapkan oleh hakikat pembelajaran bahasa Indonesia bidang kepariwisataan. (2) Tataan materi yang tertuang pada RPP guru masih banyak yang belum menyesuaikan dengan hakikat pendekatan saintifik dalam pembelajaran bahasa seperti diamanatkan pada Kurikulum 2013. (3) Pendekatan saintifik hanya dituangkan pada langkah-langkah pembelajaran pada RPP dan tidak linier dengan pengembangan bahan ajar yang mendukung pelaksanaan pendekatan saintifik tersebut. (4) Jenis teks yang direncanakan untuk diajarkan sudah sesuai dengan jenis teks yang diamanatkan oleh Kurikulum 2013. (5) Keberadaan teori kebahasaaan dan kesastraan pada RPP untuk kelas X SMK kepariwisataan kurang mendukung pengembangan kemampuan siswa secara komprehensif. Hal ini disadari oleh guru, tetapi mereka beranggapan bahwa materi tentang teori kebahasaan dan kesastraan tidak diperlukan lagi pada pengajaran bahasa Indonesia sesuai Kurikulum 2013. Hal ini tentu pandangan yang keliru karena dasar untuk memproduksi teks yang menggunakan bahasa Indonesia tentu tidak dapat lepas dari teori kebahasaan. Demikian juga dalam mengkonversi teks non fiksi ke teks fiksi (sastra) tentu harus didasarkan pada teori kesastraan.

Langkah kedua yang dilakukan pada pengembangan prototype buku ajar bahasa Indonesia untuk siswa SMK Kepariwisataan adalah menganalisis pokok bahasan bahasa Indonesia untuk disesuaikan dengan pengembangan bahan ajar Bahasa Indonesia. Langkah ini dimaksudkan untuk mengetahui bahan ajar yang sesuai dengan pokok bahasan dan sub pokok bahasan yang perlu dikembangkan pada buku ajar yang disusun. Pokok bahasan dan sub pokok bahasan tersebut tentu juga harus relevan dengan aspek pendekatan saintifik yang diamanatkan pada 
implementasi Kurikulum 2013. Alur Prototype berdasarkan hasil analisis berbagai komponen terkait seperti Kurikulum bahasa Indonesia SMK dan Kurikulum Bidang Kepariwisataan, pendekatan pembelajaran, RPP, dan karakteristik siswa, adalah (1) pemajanan bacaaan, simakan, atau pun objek yang terkait dengan kepariwisataan, (2) memahami kata-kata sulit bidang kepariwisataan yang terdapat dalam bacaan maupun simakan atau mengumpulkan kata-kata ragam kepariwisataan yang terdapat pada objek yang sedang diamati, (3) pertanyaan terkait dengan bacan, simakan, atau objek yang telah diamati siswa, (4) penjelasan atau pun eksplorasi teori tentang jenis teks yang dipakai sebagai bacaan, simakan, atau pun objek pengamatan, (5) eksplorasi tentang struktur bahasa dan ejaan, (6) Menyunting teks terdiri atas 2 kegiatan, yaitu menyunting isi dan bahasa, (7) menyusun teks, (8) menyunting teks yang disusun, (9) pemaparan teori sastra, (10) konversi teks.

\section{Prototype Bahan Ajar Bahasa Indonesia Berorientasi Dunia Kerja Pariwisata untuk Siswa klas X SMK Program Keahlian UPW}

Berdasarkan kajian teoretis dan kajian empirik seperti ditemukan di atas, maka prototype Bahan Ajar Bahasa Indonesia Berorientasi Dunia Kerja Kepariwisataan untuk Siswa Kelas X SMK Program Keahlian UPW di Kota Denpasar memiliki karakteristik ataupun komponen sebagai berikut.

a) Penggunaan pendekatan tematik-integratif dengan memakai tema kepariwisataan

Untuk membalut tema kepariwisataan ke dalam buku ajar bahasa Indonesia agar bahan ajar bahasa Indonesia yang tersusun, maka satu-satunya cara yang dapat dilakukan dengan menggunakan pendekatan tematikintegratif. Dalam kaitannya dengan ragam bahasa yang diajarkan, yaitu ragam pariwisata, maka tema yang dipakai adalah tema kepariwisataan. Untuk menopang tema ini, dapat dilakukan dengan menggunakan bahan pengamatan berupa bacaan maupun simakan yang bertema kepariwisataan. Selain itu, untuk kegiatan pengamatan lain berupa pengamatan langsung dapat digunakan objek wisata atau pun atraksi wisata atau pun kegiatan pariwisata lainnya untuk diobservasi di lapangan oleh siswa. Akan sangat ideal, jika bahan bacaan maupun simakan tersebut terintegrasi dengan mata pelajaran bidang kepariwisataan sesuai dengan jenis teks yang akan diajarkan. Relevansi jenis teks dengan pokok bahasan mata pelajaran kepariwisataan telah ditemukan pada penelitian tahap I dari rangkaian penelitian pengembangan bahan ajar ini. Hasil penelitian tersebut menjadi referensi dalam pemilihan dan pengintegrasian materi dalam pengembangan bahan ajar bahasa Indonesia.

b) Penggunaan model pengembangan bahan ajar bahasa Indonesia berbasis teks

Penggunaan model pengembangan bahan ajar Bahasa Indonesia berbasis teks dimaksudkan untuk mengembalikan hakikat belajar bahasa Indonesia itu kepada fungsi utama bahasa yaitu sebagai alat komunikasi dan sarana pembentukan kemampuan berpikir manusia. Untuk tujuan tersebut, maka bahasa hendaknya dipandang sebagai teks, bukan semata-mata kumpulan kata atau kaidah kebahasaan. Hanya teks yang mampu dipakai untuk mengungkapkan makna yang hendak disampikan kepada orang lain. Oleh karena itu, penggunaan bahasa merupakan proses pemilihan bentuk-bentuk kebahasaan untuk mengungkapkan makna tersebut. Dalam hal pengungkapan makna tersebut, bahasa tersebut bersifat fungsional, yaitu penggunaan bahasa yang tidak pernah dapat dilepaskan dari konteks karena bentuk bahasa yang digunakan itu mencerminkan ide, sikap, nilai, dan ideologi penggunanya. Dengan dasar pemikiran mengembalikan hakikat bahasa (Indonesia) kepada hakikatnya tersebut, maka bahan ajar yang disusun semestinya mengarahkan pengalaman siswa kepada pemahaman, pembentukan, dan penggunaan teks bahasa Indoensia di dalam pembelajaran.

Dalam tataran kebahasaan, teks adalah tataran kebahasaan yang paling luas. Pada teks tidak hanya sekedar menggunakan bentuk-bentuk linguistik tetapi juga harus memasukkan unsur-unsur nonlinguistik. Unsur-unsur nonlinguistik tersebut dapat berupa budaya di suatu masyarakat, sikap, rasa, dan sebagainya. Pemaduan harmonis antara unsur linguistik dan nonlinguistik dalam teks tersebut diharapkan akan memberikan pengalaman real kepada siswa untuk dapat berkomunikasi secara baik di masyarakat terutama masyarakat tempat kerjanya kelak.

c) Penggunaan pendekatan saintifik dalam implementasi pembelajaran berbasis teks

Kurikulum 2013 menekankan pada dimensi pedagogik modern dalam pembelajaran, yaitu menggunakan pendekatan ilmiah atau pendekatan saintifik. Pendekatan saintifik (scientific appoach) dalam pembelajaran meliputi mengamati, menanya, mencoba, mengolah, menyajikan, menyimpulkan, dan mencipta. Pendekatan saintifik ini diharapkan menjadikan siswa memiliki sikap ilmiah yang bebas dari prasangka dan sejenisnya sesuai dengan kriteria pendeketan saintifik yang telah digariskan. Kriteria tersebut adalah (a) substansi atau materi pembelajaran berbasis pada fakta atau fenomena yang dapat dijelaskan dengan logika atau penalaran tertentu; bukan sebatas kira-kira, khayalan, legenda, atau dongeng semata, (b) penjelasan guru, respon peserta didik, dan interaksi edukatif guru-peserta didik terbebas dari prasangka yang serta-merta, pemikiran 
subjektif, atau penalaran yang menyimpang dari alur berpikir logis (c) mendorong dan menginspirasi peserta didik berpikir secara kritis, analistis, dan tepat dalam mengidentifikasi, memahami, memecahkan masalah, dan mengaplikasikan substansi atau materi pembelajaran, (d) mendorong dan menginspirasi peserta didik mampu berpikir hipotetik dalam melihat perbedaan, kesamaan, dan tautan satu sama lain dari substansi atau materi pembelajaran, (e) mendorong dan menginspirasi peserta didik mampu memahami, menerapkan, dan mengembangkan pola berpikir yang rasional dan objektif dalam merespon substansi atau materi pembelajaran, (f) berbasis pada konsep, teori, dan fakta empiris yang dapat dipertanggungjawabkan, (g) tujuan pembelajaran dirumuskan secara sederhana dan jelas, namun menarik sistem penyajiannya.

Dengan kriteria pendekatan saintifik seperti disebutkan di atas, maka pembelajaran bahasa Indonesia beserta segenap komponennya seperti buku ajar harus menyesuaikan agar pengalaman belajar yang didapatkan siswa benar-benar bermakna bagi kehidupannya, baik kehidupan sebagai siswa maupun sebagai warga masyarakat. Buku ajar bahasa Indonesia haruslah berdasarkan fakta dan memiliki alur berpikir ilmiah agar sikap ilmiah siswa terbentuk sejak di sekolah.

d) Meningkatkan pemahaman terhadap isi materi kepariwisataan dengan tahapan pemahaman yang jelas

Salah satu penciri dari buku ajar yang akan disusun pada penelitian ini adalah buku ajar yang menjembatani pelajaran bahasa Indonesia dengan dunia kerja siswa nantinya. Jenis buku ajar bahasa Indonesia semacam itu belum ada sampai sekarang. Apalagi kurikulum 2013, yang menyamaratakan buku pelajaran setingkat SMA dan SMK. Hal ini tentu suatu yang memprihatinkan di tengah tuntutan profesionalisme makin gencar. Oleh karena itu, ragam bahasa Indonesia sesuai dunia kerja yang akan dimasuki siswa setelah mereka menyelesaikan pendidikannya sangat mendesak untuk dilatihkan. Pelajaran bahasa Indonesia tidaklah sekadar belajar tata bahasa dan kesusastraan yang lepas dari dunia kerja. Pelajaran bahasa Indonesia harus mampu menopang profesionalisme siswa kelak. Salah satu cara yang dapat ditempuh adalah menjadikan materi kepariwisataan sebagai tema dan selanjutnya menjadikan materi melajaran kepariwisataan menjadi bahan kajian mata pelajaran bahasa Indonesia dari segi kebahasaannya. Buku ajar bahasa Indonesia untuk siswa SMK Kepariwisataan harus mengajarkan ragam kepariwisataan di dalamnya. Materi kepariwisataan dijadikan sebagai pintu masuk untuk menuju ragam bahasa pariwisata. Dengan demikian, produksi kalimat sampai kepada teks, nonfiksi maupun fiksi, menunjukkan ragam kepariwisataan.

e) Memfasilitasi siswa untuk mempro-duksi teks

Ciri lain dari model buku ajar bahasa Indonesia yang perlu diperhatikan adalah memproduksi teks. Dalam hal ini, buku ajar yang disusun berisi tugas atau memberikan pengalaman kepada siswa untuk memproduksi berbagai jenis teks yang dibutuhkan dalam kehidupannya, terutama kehidupannya di dunia kerja. Teks-teks yang diproduksi pun tetap berada dalam ragam bahasa pariwisata. Latihan-latihan yang ada pada buku ajar agar lebih mengarahkan kepada produksi teks dibandingkan latihan struktur kebahasaan yang parsial dari teks.

\section{KESIMPULAN}

Hal mendasar yang perlu diperhatikan dalam penyusunan bahan ajar bahasa Indonesia berorientasi dunia kerja kepariwisataan untuk siswa SMK kepariwisataan adalah (1) ragam bahasa kepariwisataan yang relevan dengan materi pelajaran pada mata pelajaran kepariwisataan, (2) pembelajaran bahasa Indonesia yang berbasis teks sebagai bentuk ungkapan yang paling lengkap dari makna yang ingin disampaikan dengan bahasa Indonesia, (3) pendekatan tematik-integratif dan pendekatan saintifik sebagai pemadu dan penuntun pembentukan pengalaman siswa menuju ragam bahasa Indonesia kepariwisataan, dan (4) pengalaman memproduksi teks dari siswa.

Prototype semacam ini diharapkan mampu menuntun menghasilkan buku ajar yang sesuai dengan harapan karena prototype tersebut sudah valid berdasarkan penilaian ahli. Prototype yang ditawarkan ini baru merupakan langkah awal untuk sampai kepada penyusunan bahan ajar bahasa Indonesia kepariwisataan untuk siswa SMK kepariwisataan di Kota Denpasar. Oleh karena itu, masukan dari para pemerhati dan peminat tentu sangat diharapkan agar dapat ditemukan sebuah model yang tepat. 


\section{DAFTAR PUSTAKA}

Depdikbud.1985. Pedoman Penyusunan Modul. Jakarta. Badan Pengembangan Pendidikan-Depdikbud.

Dick, W. and Cary Lou. 1990. The Systematic Design of Instruction. 3rd Ed. USA: Harper Collins Publisher

Dudley Evans, T \& St. Johnson M. 1998. Development in ESP: A Multi-Disiplinary Approach. Cambridge : Cambridge University Press.

Hadley, A.O. 1993. Teaching language in contaxt. Boston: Heile \& Helee.

Halliday, MAK. 1978. Language as sosial semiotic: The Sosial interpretation of language and meaning. London: Edward Arnold.

Hutchinson,T \& Waters, A. 1987. English for Specific Purpose: A Learning-Centered Approach. Cambridge : Cambridge University Press.

Jorgensen, M.W. and Phillips, L.J. 2007. Analisis wacana: Teori dan metode, terjemahan Abdul Syukur Ibrahim. Yogyakarta: Pustaka Pelajar.

Kunandar. 2007. Guru Profesional: Implementasi Kurikulum Tingkat Satuan Pendidikan (KTSP) da Persiapan Menghadapi Sertifikasi Guru. Jakarta: PT RajaGrafindo Persada.

Rahmat Darmawan. 2009. Pembelajaran Bahasa Indonesia untuk Bidang Pariwisata di Akademi Pariwisata Medan. Medan : Sekolah Pasca Sarjana, Universitas Sumatra Utara (Tesis, tidak diterbitkan)

Russel, J.D. 1974. Modular Instructional. A Guide to the Design, Selection, Utilization and Evaluation of Modular Materials. Minneapolish, Minnesota: Burgess. 